\title{
Contributing to communicable diseases intelligence management in Canada: CACMID meeting, March 2007, Halifax, Nova Scotia
}

\author{
Shamir Mukhi PhD PEng, Jeff Aramini PhD DVM, Amin Kabani MD MBA
}

\begin{abstract}
S Mukhi, J Aramini, A Kabani. Contributing to communicable diseases intelligence management in Canada: CACMID meeting, March 2007, Halifax, Nova Scotia. Can J Infect Dis Med Microbiol 2007;18(6):353-356.
\end{abstract}

In the spring of 2003, the Public Health Agency of Canada (then, Health Canada) partnered with several provincial/territorial and regional public health stakeholders to improve pan-Canadian public health surveillance, communications and response through the application of new technologies. This resulted in the creation of the Canadian Network for Public Health Intelligence (CNPHI), a comprehensive framework of applications and resources designed to fill critical gaps in Canada's national public health infostructure. Over the past four years, the CNPHI has evolved into Canada's only panCanadian public health information management system. With over 2000 registered users, the current CNPHI environment consists of more than 30 integrated applications and systems that can be loosely categorized into four functional groups: data exchange; data analysis and integration; communication, collaboration and coordination; and knowledge management. Despite poor data repositories, legacy information management systems, and the lack of standards and agreements, the CNPHI has demonstrated that much can be accomplished in these areas. Over the next decade, significant barriers impeding additional advances will be bridged through the implementation of the Electronic Health Record, and through ongoing efforts to address gaps in standards, and data- and information-sharing agreements. Together with new technologies coming on-line, opportunities to further enhance public health surveillance and response will be limited only by one's imagination.

Key Words: Analysis; Data collection; Outbreak management; Rapid communication; Response; Surveillance

$\mathrm{O}$ ver the past few years, a number of widely publicized health events have sparked much reflection, debate and subsequent action relating to the state of public health information management in Canada. Two large waterborne outbreaks (an Escherichia coli outbreak in Walkerton, Ontario, in 2000 and a cryptosporidiosis outbreak in North Battleford, Saskatchewan in 2001), the 2003 severe acute respiratory syndrome (SARS) episode in Toronto, Ontario, and fears of bioterrorism since September 2001 have all prompted local, provincial/territorial and federal health authorities to critically assess their surveillance and response capacities with respect to information management.

New technologies and informatics are central to improving public health surveillance and response capacities at all levels of government. Data extraction and exchange tools; sophisticated modeling and forecasting methods; and Web-based

\author{
Contribuer à la gestion des renseignements sur \\ les maladies transmissibles au Canada : \\ Le congrès d'AMMI Canada à Halifax, en \\ Nouvelle-Écosse, en mars 2007
}

\begin{abstract}
Au printemps 2003, l'Agence de la santé publique du Canada (alors Santé Canada) s'est associée à plusieurs intervenants en santé publique provinciaux, territoriaux et régionaux afin d'améliorer la surveillance pancanadienne de la santé publique, les communications et les réactions à cet égard grâce à l'application des nouvelles technologies. La création du Réseau canadien de renseignements sur la santé publique (RCRSP) en a résulté, une structure complète d'applications et de ressources conçues pour corriger les lacunes considérables de l'infostructure nationale de la santé publique au Canada. Depuis quatre ans, le RCRSP est devenu le seul système de gestion canadien de l'information en santé publique. Avec plus de 2000 utilisateurs inscrits, l'environnement actuel du RCRSP se compose de plus de 30 applications et systèmes intégrés qui peuvent être classés en quatre grands groupes fonctionnels : échange de données, analyse et intégration des données, communications, collaboration et coordination, et gestion du savoir. Malgré des dépôts de données déficients, des systèmes de gestion de l'information traditionnels et l'absence de normes et d'ententes, le RCRSP a démontré qu'on peut beaucoup accomplir dans ces secteurs. Au cours des dix prochaines années, on vaincra d'importants obstacles ralentissant les progrès grâce à l'adoption du Dossier de santé électronique et aux efforts continus pour combler les écarts dans les normes et les ententes sur le partage des données et de l'information. Avec l'arrivée de nouvelles technologies Internet, les possibilités d'améliorer la surveillance de la santé publique et le délai de réaction ne seront plus limités que par notre imagination.
\end{abstract}

Public Health Agency of Canada

Correspondence: Dr Shamir Mukhi, Public Health Agency of Canada, 1015 Arlington Street, Winnipeg, Manitoba R3E 3R2.

Telephone 204-771-4698, fax 204-789-7039, e-mail shamir_nizar_mukhi@phac-aspc.gc.ca 
infinite supply of new technologies, it is critical that, in the development and implementation of new public health information systems, the ultimate purpose for harnessing new technologies be clearly defined and understood.

An assessment of the pan-Canadian public health environment revealed that improvements in information management are required at many points, from surveillance (including data exchange and analysis), to information exchange and intelligence sharing, knowledge management and response coordination. When considering surveillance, intelligence sharing and communication among and between stakeholders is often overlooked as a piece of the surveillance puzzle. Contrary to this, communication is probably the most critical component of an effective public health surveillance system. This understanding of health surveillance is in line with Naylor's definition in his 2003 report (1), in which he reflects upon the 2003 SARS episode in Canada:

(Health Surveillance is) the tracking and forecasting of any health event or health determinant through the continuous collection of high-quality data, the integration, analysis and interpretation of those data into surveillance products (for example reports, advisories, alerts, and warnings), and the dissemination of those surveillance products to those who need to know... (1).

\section{Development and implementation of the Canadian Network} for Public Health Intelligence

In the spring of 2003, the Public Health Agency of Canada (then, Health Canada) partnered with several provincial/territorial and regional public health stakeholders to improve the 'business' of public health in Canada through the application of new technologies. At that time, Health Canada had already led the development and implementation of a successful provincial/territorial case management system (Integrated Public Health Information System [IPHIS]) and a global media tracking alerting system (Global Public Health Intelligence Network [GPHIN]). Stakeholders identified the need to complement the IPHIS and the GPHIN through the development and implementation of a pan-Canadian system to facilitate surveillance, communication and response.

As noted previously, with so many technical options available, the real challenge becomes matching the right technology with the right problem. A number of guiding principles and criteria were developed to assist in choosing the right technologies:

- Where possible, make use of existing legacy systems and applications by creating interfacing adapters, and single sign-on methods to provide a seamless user experience;

- Develop systems that are flexible and scalable to meet changing public health needs over time;

- Adhere to international standards when they exist and attempt to create new standards where they do not;

- Implement user interfaces that are intuitive and appropriate for the intended users;

- Choose technologies that align with current fiscal realities; and

- Implement scalable hosting infrastructure that allows for expansion, using clustered setups for inherent redundancy and load balancing to manage increasing traffic loads during critical periods (eg, during a disease outbreak).

Clearly, there are many technologies that could (if applied correctly) contribute to effective public health information management. But when a deliverable can be achieved with immediate buy-in rather than iterative nonsatisfying outcomes, or a function can be accomplished with a few lines of code rather than thousands, the appropriate choices should be made. Why use a backhoe to plant a flower when a small shovel will do?

With the guiding principles and criteria in place, the Government of Canada funded the development and implementation of a pan-Canadian public health surveillance and response system. The Canadian Network for Public Health Intelligence (CNPHI) is a comprehensive framework of applications and resources designed to fill critical gaps in Canada's national public health infostructure. Guided by multijurisdictional program-led working groups, the goal of the CNPHI is to reduce the occurrence of human illness associated with infectious diseases by developing tools that will enhance the surveillance, communications and response capacities of public health stakeholders.

The CNPHI was conceived, not as an information management, information technology, knowledge management (IM/IT/KM) solution to meet a specific set of narrow public health needs, but as an innovative program that marries the evolving practice and science of public health with the growing capabilities offered by Web-enabled information technologies. The ultimate goal of the CNPHI is to enhance day-to-day public health delivery by empowering public health stakeholders with innovative IM/IT/KM resources. It was felt that it was necessary to not only address gaps raised by Dr Naylor following the SARS episode, but also to anticipate how public health needs will evolve, and create an organic infostructure that embraces growth and change. Meeting a number of objectives was considered essential to the CNPHI's ultimate success:

- Integration of alerting, surveillance, response, and data and information sharing into a comprehensive IM/IT/KM framework, thus providing a seamless environment of resources to enhance the continuum from detection, through investigation, to response and evaluation;

- Integration of traditionally siloed disciplines including epidemiology, microbiology, environmental sciences, animal health, chronic diseases and public health security;

- Empowerment of public health stakeholders with knowledge management and decision support resources (Geographic Information Systems [GIS] and infectious disease modeling) to enhance evidence-based decision-making;

- Integration of public health practitioners (regional, provincial/territorial and national), the scientific community (government, industry and academia), and the social/policy/administrative communities;

- Implementation of resources to facilitate and foster national and international team development and communications;

- Leveraging of legacy IM/IT/KM platforms and integration with a broad spectrum of software 
TABLE 1

The Canadian Network for Pubic Health Intelligence's (CNPHI's) solutions to many of today's public health information management challenges

\begin{tabular}{|c|c|c|}
\hline Today's challenge & CNPHI solutions & CNPHI examples \\
\hline \multicolumn{3}{|l|}{ Data exchange } \\
\hline $\begin{array}{l}\text { - Few central repositories } \\
\text { - Legacy systems } \\
\text { - Few data standards } \\
\text { - Lack of data-sharing agreements }\end{array}$ & $\begin{array}{l}\text { - Enable automated data exchange and } \\
\text { manual data entry } \\
\text { - Accommodate legacy systems and nonstandard } \\
\text { data formats } \\
\text { - Accommodate jurisdictional needs } \\
\text { - Anticipate new systems }\end{array}$ & $\begin{array}{l}\text { - National Enteric Surveillance Program Web- } \\
\text { application (enables both manual and automated } \\
\text { data entry) } \\
\text { - Canadian Early Warning System (receives } \\
\text { real-time data from multiple data providers) }\end{array}$ \\
\hline \multicolumn{3}{|l|}{ Data analysis and integration } \\
\hline $\begin{array}{l}\text { - Manually intensive processes } \\
\text { - Specialized skills/tools required (SAS, GIS, etc) } \\
\text { - Results viewable and accessible by few } \\
\text { - Poor standardization of methods }\end{array}$ & $\begin{array}{l}\text { - Automated results } \\
\text { - Configurable, flexible and intuitive } \\
\text { - Hierarchical data analysis and results accessibility } \\
\text { - Role-based access and functionality } \\
\text { - Anticipate changing needs }\end{array}$ & $\begin{array}{l}\text { - FluWatch Web application (enables both manual } \\
\text { and automated data entry; conducts automated } \\
\text { analysis; role-based and jurisdictional-based } \\
\text { access and features) }\end{array}$ \\
\hline \multicolumn{3}{|l|}{ Communication, collaboration and coordination } \\
\hline $\begin{array}{l}\text { - Growing number of multidisciplinary and } \\
\text { multijurisdiction committees, work-groups, etc } \\
\text { - Difficult to communicate, coordinate and } \\
\text { share information using Intranet services } \\
\text { - Difficult to access and manage information } \\
\text { when away from the office }\end{array}$ & $\begin{array}{l}\text { - Intuitive Web-enabled information portals } \\
\text { - Targeted communications } \\
\text { - Configurable and flexible systems } \\
\text { - Role- and user-based information access } \\
\text { - Provide review and information control processes, } \\
\text { if required } \\
\text { - Anticipate integration with Panorama, Epi-X, etc }\end{array}$ & $\begin{array}{l}\text { - Pan-Canadian alerting system (enables targeted } \\
\text { and role-based sharing of alerts) } \\
\text { - Collaboration centres (enables group-specific } \\
\text { Web portals for data and information } \\
\text { management and sharing; customizable to } \\
\text { meet group-specific needs. } \\
\text { - Dynamic Event Management System: intuitive } \\
\text { system to facilitate Incident Command System } \\
\text { operations }\end{array}$ \\
\hline \multicolumn{3}{|l|}{ Knowledge management } \\
\hline $\begin{array}{l}\text { - Increasingly demanding to organize, store } \\
\text { and access growing volumes of information } \\
\text { (references and texts; contact lists and } \\
\text { inventories; and protocols and training } \\
\text { materials) }\end{array}$ & $\begin{array}{l}\text { - Intuitive Web-enabled information portals } \\
\text { - Accommodate jurisdictional needs } \\
\text { - Role- and user-based access } \\
\text { - Anticipate integration with other online knowledge } \\
\text { management systems }\end{array}$ & $\begin{array}{l}\text { - Emergency Contacts System (flexible and } \\
\text { configurable information repository; enables } \\
\text { targeted and role-based access to information) } \\
\text { - Access to third-party information sources (eg, } \\
\text { the CNPHI Gideon portal) }\end{array}$ \\
\hline
\end{tabular}

GIS Geographic information systems; SAS Statistical analysis software

applications (eg, the IPHIS, the GPHIN, laboratory information management systems, event management systems and bioinformatics);

- Evolution of surveillance toward automated data exchange and real-time anomaly detection;

- Anticipate the growth of handheld devices and wireless Internet;

- Anticipate IM/IT/KM needs of provincial/territorial, and the Public Health Agency of Canada Winnipeg command and control operations centres; and

- Ability to integrate with, and adapt to, ongoing Infoway initiatives (eg, Panorama, telemedicine and Electronic Health Records [EHRs]).

The CNPHI's solutions to many of today's public health information management challenges

Over the past four years, the CNPHI has evolved into Canada's only pan-Canadian public health information management system. Among the CNPHI's more than 2000 registered users, including representation from each of Canada's regional health authorities, 100 to 300 individuals access one or more resources from the CNPHI's growing suite of Web-based resources on a daily basis. The CNPHI environment now consists of more than 30 integrated applications and systems that can each be loosely categorized into one of four functional groups: data exchange; data analysis and integration; communication, collaboration and coordination; and knowledge management. Table 1 describes the challenges identified, solutions provided and examples of each.

Lesson learned through the CNPHI development and implementation

The development and implementation of the CNPHI highlighted the need for new approaches to public health IM/IT/KM resource development and implementation. Most stakeholders had had negative IM/IT/KM project experiences in the past. For the most part, public health program stakeholders expressed dissatisfaction with the traditional IT approach to application development. They believed that the traditional approach of endless requirements collection and documentation was tedious and unproductive. Furthermore, they believed that the end results rarely met expectations.

In an attempt to break this unproductive cycle, a programcentric approach was developed. The CNPHI strategy brings program end users (epidemiologists, microbiologists, administrators, etc) into the core project team. Individuals with experience and training in the program areas were recruited to work with their regional, provincial/territorial and national 
colleagues, and with a team of engineers and computer scientists to guide end users through the entire business cycle, from needs assessment to product implementation.

For each of the business cycle stages, new approaches were developed and tested. Most importantly, it became apparent that rarely are end user needs well defined from the onset. Hence, the business cycle used is based on an iterative and visual approach to needs assessment. The primary objective is to provide an environment in which end users can explore options and, together with the application development team, create innovative solutions. The end users are buffered from the traditional tedious IT processes of formal change requests and endless documentation during development stages. Applications evolve quickly and versions are released rapidly. The end result of this approach has been overwhelming buy-in and end-user ownership. It has resulted in an environment of trust, respect and mutual appreciation.

Another key element of the strategy developed is the building block approach to IM/IT/KM resource development. Although infectious disease surveillance and response programs have developed in a siloed environment (particularly at the federal level), there are many similarities in business processes (data flow, analysis needs, communication needs, etc) among the many disease-specific areas. The traditional siloed approach has resulted in fragmented IM/IT/KM systems and, as a byproduct, has encouraged fragmented business approaches. Fragmented public health businesses are the main challenge to establishing the much sought-after 'integrated' approach to public health surveillance and response.

The CNPHI approach leverages similarities in business processes among program areas to achieve considerable efficiencies in IM/IT/KM resource delivery. The developed framework allows for the rapid configuration and implementation of solutions. Common business needs include real-time data extraction, analysis and decision support resources (GIS, charting and graphing); structured alerting and notification; team communication and collaboration; syndromic surveillance; laboratory-based surveillance; and quality assurance processes. The interaction with many program areas has resulted in a rich and diverse suite of infostructure building blocks that has provided the opportunity to leverage tools developed for one specific program across all program areas. Not only has this approach been well received by programs, it is also contributing to standardization and integration in business functions across public health programs.

The adoption of a program-centric, stepwise approach to IM/IT/KM implementation is intended to help program areas achieve an integrated approach to public health surveillance and response. As mentioned previously, in many respects new technologies can facilitate change in how the business of public health is conducted.

\section{Considerations and future opportunities}

Today's rapidly advancing information technology and management environment will inevitably lead to substantial changes in the business of public health. For example, consider the potential future opportunities relating to public health surveillance:

- In Canada, it is expected that most, if not all, health records will be in electronic format and available on-line to appropriate individuals within the next decade or so.
The EHRs provide the opportunity to improve both clinical care and public health through advances in evidence-based medicine and evidenced-based public health. Envision a system that automatically recommends to a physician a differential diagnosis list, based not only on a patient's presenting symptoms, but also on current population disease dynamics in his or her community. Likewise, envision the same system aggregating EHR data, providing surveillance information to local public health officials in real time and allowing the public health official to push requests for additional required data elements (history, tests, etc) down to the physician to test a hypothesis;

- Consider air quality and drinking water advisories based not only on air and water sampling results but also on real-time health parameters reported from a given community (eg, emergency room visits, physician visits, sales of over-the-counter medications and telehealth activity). Current air and water quality guidelines assume the offending chemical or microbe can be detected in the air or water in a timely manner. However, some tests are not performed daily, or not at all. What about pollutants and chemicals that cannot yet be measured?

- Occasionally, grocery store receipts are used to help identify a common food item during a presumed foodborne outbreak. Could electronic transactions (which most are these days) and health records be automatically monitored to identify a suspect food item or restaurant?

- Wireless devices are now available to monitor individual health parameters in real time, such as heart rate and respiratory rate. In the event of a heat wave, could real-time surveillance of the elderly and shut-ins help direct public health action?

- Many infectious diseases in Canada can be traced to travel to a foreign country. Could air and sea travel data be monitored and integrated with health information to help identify risk areas outside Canada's borders?

Given the current state of public health in Canada, the CNPHI has demonstrated that much can be accomplished. Despite poor data repositories, legacy information management systems, and the lack of standards and agreements, the CNPHI has demonstrated that tremendous gains are possible in the areas of data exchange; data analysis and integration; communications, collaboration and coordination; and knowledge management. Over the next decade, significant barriers impeding additional advances will be bridged through the implementation of the EHR and through ongoing efforts to address gaps in standards, and data- and information-sharing agreements. Together with new technologies coming on-line, opportunities to further enhance public health surveillance and response will be limited only by one's imagination.

\section{REFERENCES}

1. Naylor D, ed. Learning from SARS: Renewal of public health in Canada. Ottawa: Health Canada, 2003.

<http://www.phac-aspc.gc.ca/publicat/sars-sras/naylor/>

(Version current at October 18, 2007). 


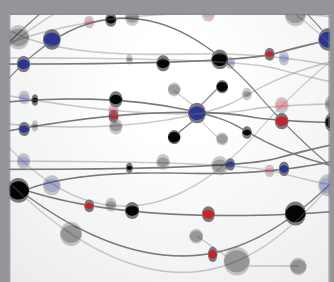

The Scientific World Journal
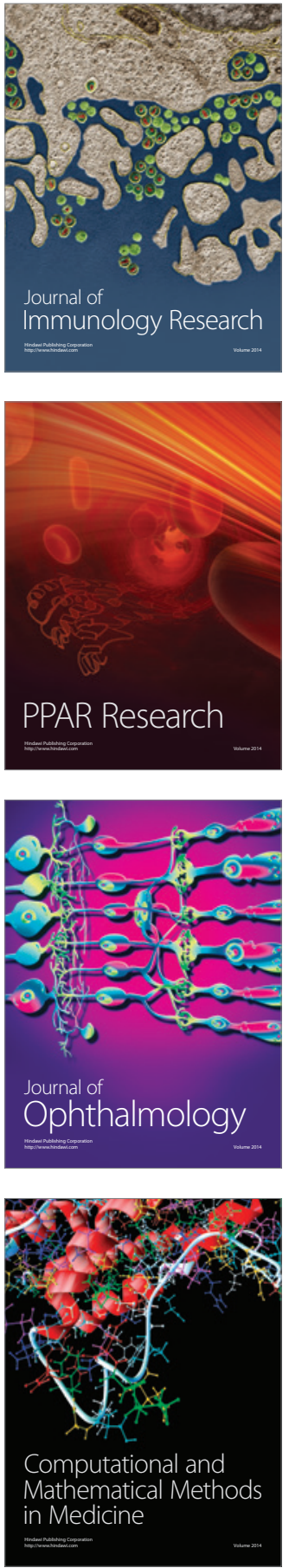

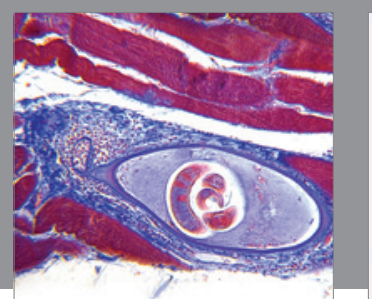

Gastroenterology Research and Practice

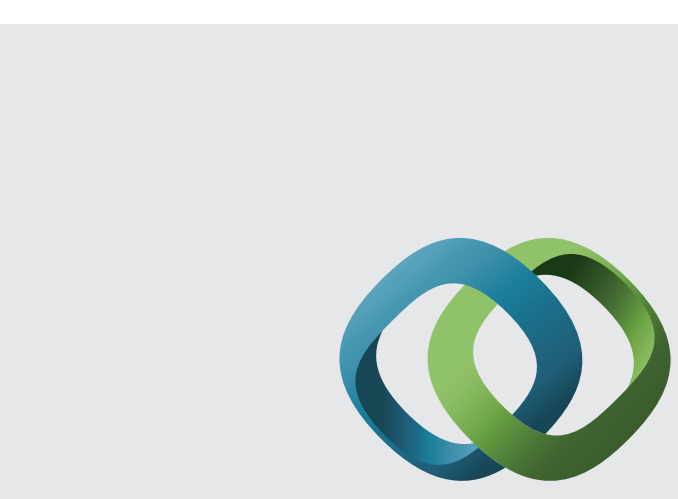

\section{Hindawi}

Submit your manuscripts at

http://www.hindawi.com
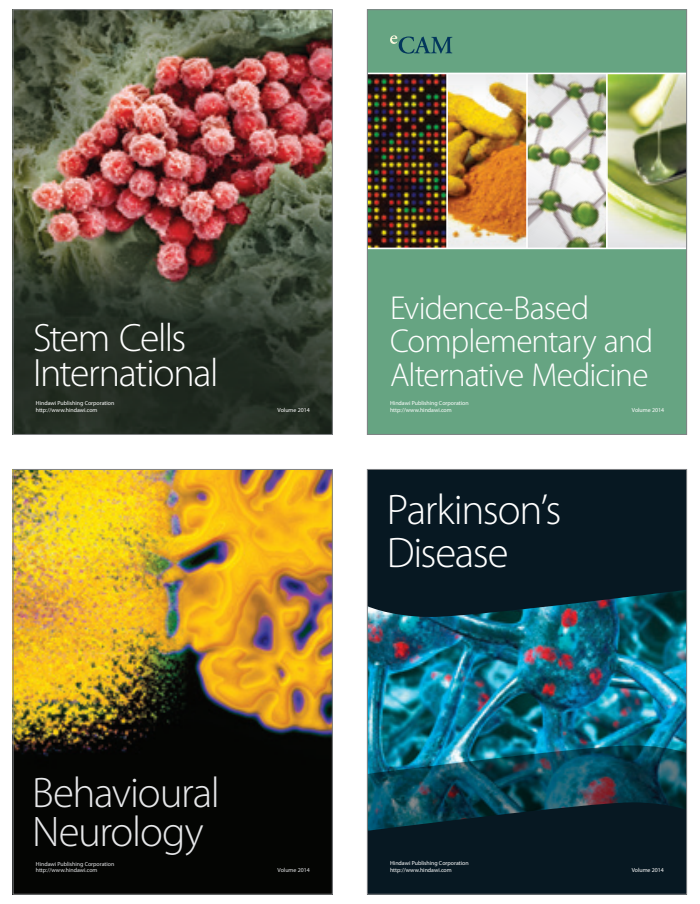
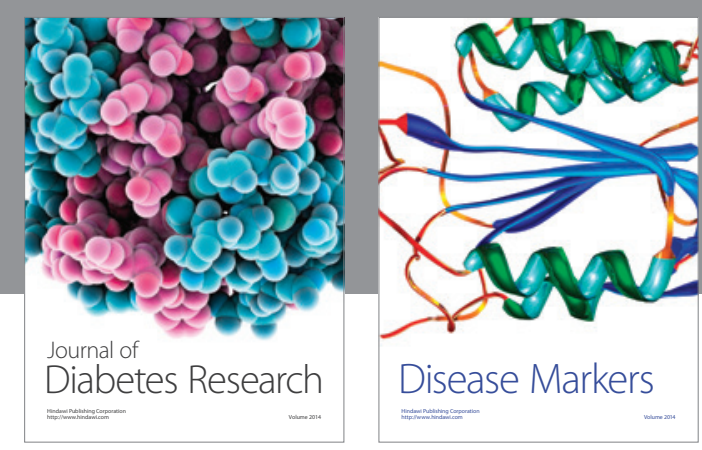

Disease Markers
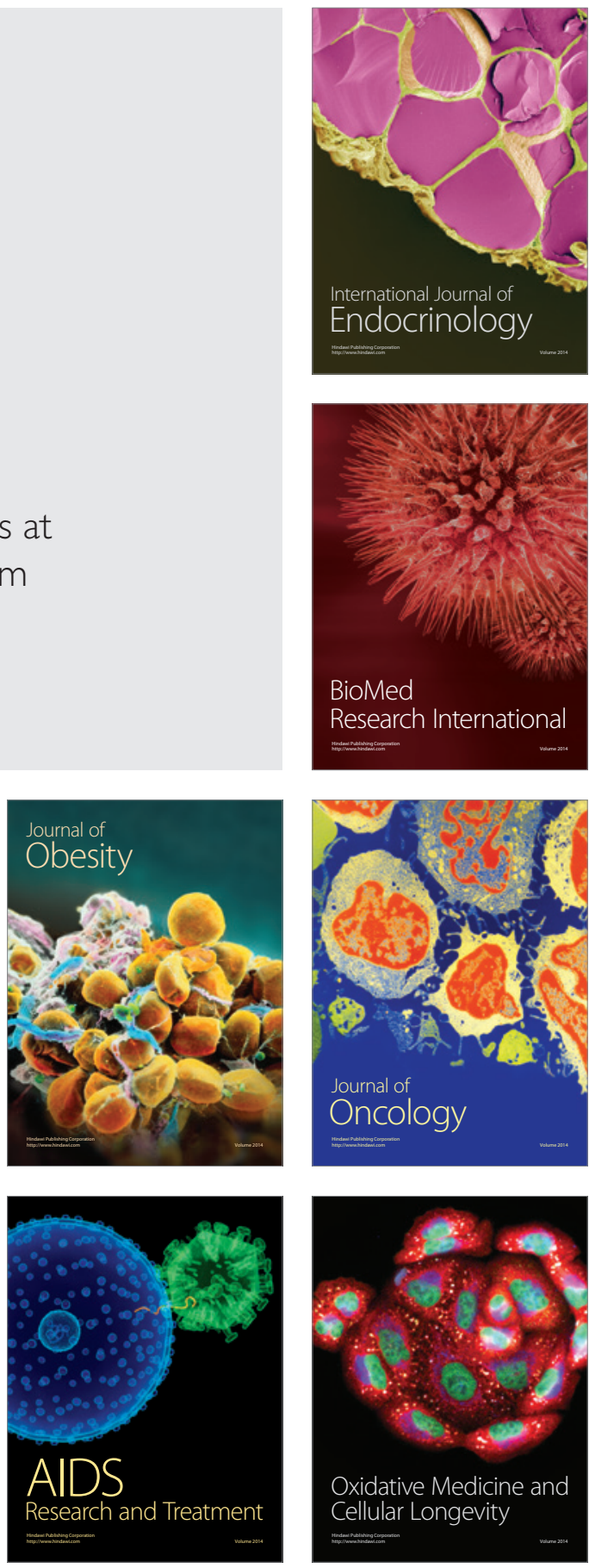